University of Nebraska - Lincoln

DigitalCommons@University of Nebraska - Lincoln

May 2007

\title{
Fitting disposition codes to mobile phone surveys: experiences from studies in Finland, Slovenia and the USA
}

\author{
Mario Callegaro \\ University of Nebraska - Lincoln \\ Charlotte Steeh \\ Centers for Disease Control and Prevention, Atlanta, USA \\ Trent D. Buskirk \\ St Louis University, USA \\ Vasja Vehovar \\ University of Ljubljana, Slovenia \\ Vesa Kuusela \\ Statistics Finland, Helsinki, Finland \\ See next page for additional authors
}

Follow this and additional works at: https://digitalcommons.unl.edu/gallup_workingpapers

Part of the Quantitative, Qualitative, Comparative, and Historical Methodologies Commons

Callegaro, Mario; Steeh, Charlotte; Buskirk, Trent D.; Vehovar, Vasja; Kuusela, Vesa; and Piekarski, Linda, "Fitting disposition codes to mobile phone surveys: experiences from studies in Finland, Slovenia and the USA" (2007). UNL-Gallup Working Papers Series. 1.

https://digitalcommons.unl.edu/gallup_workingpapers/1

This Article is brought to you for free and open access by the Gallup Research Center (GRC) at DigitalCommons@University of Nebraska - Lincoln. It has been accepted for inclusion in UNL-Gallup Working Papers Series by an authorized administrator of DigitalCommons@University of Nebraska - Lincoln. 


\section{Authors}

Mario Callegaro, Charlotte Steeh, Trent D. Buskirk, Vasja Vehovar, Vesa Kuusela, and Linda Piekarski 


\title{
Fitting disposition codes to mobile phone surveys: experiences from studies in Finland, Slovenia and the USA
}

\author{
Mario Callegaro, \\ University of Nebraska, Lincoln, USA \\ Charlotte Steeh, \\ Centers for Disease Control and Prevention, Atlanta, USA \\ Trent D. Buskirk, \\ St Louis University, USA \\ Vasja Vehovar, \\ University of Ljubljana, Slovenia \\ Vesa Kuusela \\ Statistics Finland, Helsinki, Finland \\ and Linda Piekarski \\ Survey Sampling Inc., Fairfield, USA
}

[Received July 2005. Final revision August 2006]

\begin{abstract}
Summary. Using mobile phones to conduct survey interviews has gathered momentum recently. However, using mobile telephones in surveys poses many new challenges. One important challenge involves properly classifying final case dispositions to understand response rates and non-response error and to implement responsive survey designs. Both purposes demand accurate assessments of the outcomes of individual call attempts. By looking at actual practices across three countries, we suggest how the disposition codes of the American Association for Public Opinion Research, which have been developed for telephone surveys, can be modified to fit mobile phones. Adding an international dimension to these standard definitions will improve survey methods by making systematic comparisons across different contexts possible.
\end{abstract}

Keywords: Mobile phone households; Mobile phone surveys; Non-response; Response rates calculation

\section{Introduction}

In Europe increasingly more research institutes routinely make calls to mobile phones that are included in their sample frames (Beck et al., 2005; Kim and Lepkowski, 2002). Despite initial reluctance in the USA, some mobile phone surveys have also been conducted as the percentage

Address for correspondence: Mario Callegaro, Gallup Research Center, 4th Floor, 200 North 11th Street, Lincoln, NE 68588-0241, USA.

E-mail: mca@unlserve.unl.edu 
of mobile phone households becomes increasingly difficult to ignore (Lavrakas, 2005). Mobile phone surveys pose unique challenges for survey researchers everywhere. Many features of the mobile phone are new, such as text messaging, or have functions that are different from similar features on a fixed line phone. Since procedures for using mobile phones in surveys are largely uncharted, it is important to be able to make modifications to standard routines throughout the interviewing period and then to gauge the quality of the data by comparing outcome rates for mobile phones with outcome rates in traditional telephone surveys. The accurate and consistent calculation of these rates - especially response rates - and the successful implementation of responsive survey designs depend on the existence of disposition codes that meaningfully describe the results of individual call attempts as well as widely accepted outcome rate formulae. However, both of these conditions were not satisfied until the late 1990s.

The absence of standards in computing response rates had been recognized since the 1970s (American Statistical Association, 1974; Kviz, 1977), but it was not until 1982 that the Council of American Survey Research Organizations made the first effort to develop practical guidelines for the survey industry (Council of American Survey Research Organizations, 1982; Frankel, 1983). In 1998, the American Association for Public Opinion Research (AAPOR) published standard formulae for response and other outcome rates, and, for the first time, included final disposition codes for sample units in random-digit dial (RDD) telephone and in-person household surveys. The aim was to

'avoid this babel of survey disposition codes, and to allow the comparable reporting of final dispositions and the consistent calculation of outcome rates'

(American Association for Public Opinion Research (1998), page 5). As a way to impose these standards on the profession, the AAPOR required their use by researchers wanting to publish in its journal, Public Opinion Quarterly. Subsequently other journals, such as the International Journal of Public Opinion Research, Social Science Research and the American Political Science Review, also required researchers to report survey results using the AAPOR standards. After 2 years, the AAPOR updated the dispositions and added codes for mail surveys of specifically named people (American Association for Public Opinion Research, 2000). An EXCEL spreadsheet file was also made available on the AAPOR Web site to help researchers to calculate response rates in a standardized manner. A third edition of the standards was released in 2005, with more detailed descriptions of the disposition codes and some updates (American Association for Public Opinion Research, 2005), and a fourth edition that included final disposition codes for Internet surveys of specifically named people followed quickly (American Association for Public Opinion Research, 2006). These standards were the only ones that were broadly available until the Institute for Social and Economic Research in the UK proposed codes first for personal interview surveys (Lynn et al., 2001, 2002) and then for telephone surveys as well (Lynn et al., 2006).

To suggest how the AAPOR disposition codes for RDD land-line telephone surveys can be modified, added to and clarified for a new technology, we look at surveys that have been conducted in three countries: Finland, the USA and Slovenia. Although the AAPOR codes were developed specifically for RDD surveys, we do not see why they cannot also apply to surveys using list and directory samples that are more common in countries other than the USA. For the time being, however, in the absence of comprehensive directories of mobile phone numbers in most countries, samples of mobile phone subscribers will have to be drawn by using RDD methods. The surveys that we have chosen as our test cases were carried out in 2003 and 2004. The US study was part of an experimental comparison of two independently conducted RDD surveys, one based on a cellular number frame and the other on a traditional, fixed line frame. Although a survey that is conducted by mobile phone can be either interviewer administered or 
self-administered (via text messaging prompts or the mobile phone's Internet capabilities), we shall limit out discussion to surveys that are carried out by interviewers.

We join others who have discussed how response rates are calculated (Ezzati-Rice et al., 2000; McCarty, 2003; Platek and Gray, 1986), but our primary emphasis is on the disposition codes that go into the formulae. These codes must reflect the relevant survey environment closely for the calculations to be accurate. Since technological developments are changing the survey environment, we demonstrate one way that the demands of new technologies can be blended with our time-tested procedures to ensure that telephone surveys remain a legitimate method of data collection. The efforts serve six purposes. We will have

(a) provided disposition codes and estimates of outcome rates that are consistent from one mode to another,

(b) set the discussion within an international context,

(c) extended the codes to list and directory samples as well as RDD,

(d) made the case that interim disposition codes are as important as final codes,

(e) suggested how the efficiency of call scheduling and other survey procedures can be improved and

(f) showed an adaptation of our procedures that will help to maintain the telephone as a viable mode of administration into the future.

In the next section we describe the effect of both the penetration and the technology of mobile phones on traditional telephone surveys. These descriptions will serve in Section 3 as the basis for our recommendations for new codes or modifications to current AAPOR codes. In Section 4 we illustrate how these codes can be used to compute outcome rates by using data from the three international surveys, and we complete the paper with concluding remarks that reflect on the uses of these disposition codes and the future of mobile phone surveys worldwide.

\section{The effect of mobile phones on telephone sample surveys}

The international growth in mobile phone usage brings both opportunity and challenge for traditional surveys that use 'telephone number' as a sampling unit. In this section we shall provide more specific details on the changing telephony landscape worldwide and on the increasing penetration of mobile phones. We also illustrate some of the differences between mobile and land-line telephones that may contribute to both the analytic and the process complexities that occur in surveys of mobile phone subscribers. Addressing all of the details of these complexities is beyond the scope of this paper, but we shall try to summarize the most important technical aspects here to explain the need for modifications of the existing disposition codes.

\subsection{The new telephone landscape - a look at current mobile phone use}

The penetration rates of mobile phones are rapidly increasing in many countries, led in 2004 by Luxembourg, Italy, Sweden, Israel, Hong Kong and Taiwan (International Telecommunication Union, 2004). An increasing percentage of households are becoming mobile phone only, posing a coverage problem for traditional telephone surveys (Callegaro and Poggio, 2006; Kim and Lepkowski, 2002). Fig. 1 shows the percentage of households that are mobile phone only in European countries and in the USA. The data were collected at the beginning of 2004 (Ipsos, 2004; Tucker et al., 2005a, b; Vehovar et al., 2004).

The data for the 15 European Union countries were collected by Ipsos in a face-to-face (high coverage rate) survey with sample sizes ranging from 1000 for small nations such as Luxembourg and Ireland to 5000 for bigger nations such as the UK, France, Spain, Italy and 


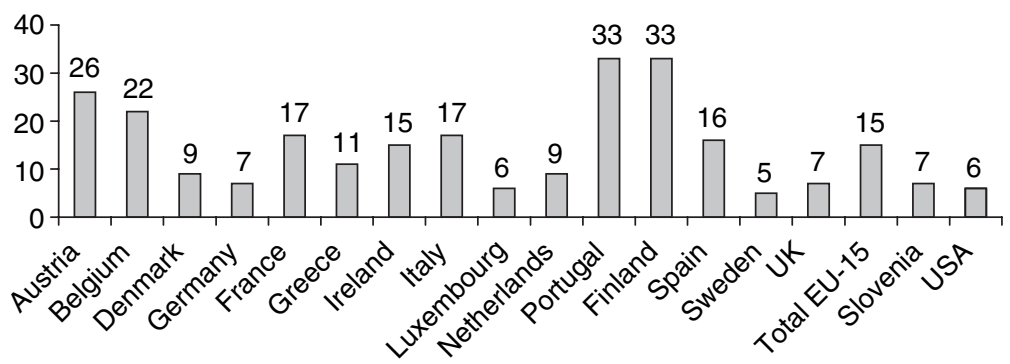

Fig. 1. Mobile-phone-only households in Europe and in the USA-2004

Germany. For all other nations the sample size was 2000. Rates for some nations (e.g. Italy, Finland, the UK and France) were cross-validated by using estimates based on data from other sources such as official statistics. Variations between the national estimates generally reflect variations on many key factors including fixed telephony penetration rates, the presence of fixed telephone monopolies, the cost of mobile relative to fixed line services, the number of mobile phone companies, competition between mobile and fixed phone companies and the percentage of prepaid contracts. The merger of large cellular phone providers now occurring in the USA promises to lessen the variability in these factors across states and regions there.

The increasing reliance of adults throughout Europe, Asia and North America on mobile phone communication means that surveys that are restricted to land-line telephone numbers will be subjected over time to greater undercoverage errors and will risk becoming increasingly less representative of general adult populations. If national lists of mobile phone numbers become more readily available across countries, researchers may be able to improve the efficiency of sample designs that are based on them, but challenges that are raised by the personal nature of the mobile phone may in fact counterbalance the positive impact of frame identifiability.

In some countries, the number of mobile phone subscribers exceeds the size of the target population causing frame overcoverage that should be addressed to avoid biased estimates. Specifically, the use of global system for mobile communications technology and subscriber identification module (SIM) cards in Europe and elsewhere has contributed to overcoverage in mobile phone number frames. The reason is because, with the advent of prepaid contracts, many users own multiple SIM cards (i.e. different mobile phone numbers) that can be used interchangeably with a single mobile phone handset. In particular, in 2002, it was estimated that in Italy $20-25 \%$ of mobile phone users owned more than one SIM card and thus had more than one mobile phone number (Costabile and Addis, 2002). In Slovenia the percentage is estimated to be around 12-16\% (Vehovar et al., 2004). In 2001 Oftel (2001) estimated that $7 \%$ and $4 \%$ of mobile phone users in Finland and Portugal respectively owned more than one phone number. Certainly by 2006 these percentages have only increased.

\subsection{Mobile phone subscribers - a new paradigm for random-digit dialling telephone surveys}

The principal difference between land-line and mobile phones lies in the fact that a land-line telephone number accesses a household that may contain multiple adults whereas a mobile number primarily accesses a single individual (see Lynn et al. (2006) for a similar assessment). Exceptions may occur if mobile telephones are exchanged between family members, especially between parents and teenage children. In the US comparative study, $93 \%$ of respondents in the cell phone survey and $79 \%$ of respondents in the land-line survey who own a cell phone say that they are the primary user of the mobile phone. Nevertheless, there is some evidence of sharing. 
In the February 2004 supplement to the Current Population Survey a substantial percentage of respondents in multiperson households with at least one cellular phone stated that the phone would be answered by more than one person. The percentage declines as the number of cellular phones in the household increases (Tucker et al., 2005b). In contrast, there is very little evidence of sharing in European countries where the penetration rate for mobile phones is higher.

In any event, the change from the household to the individual level means that the random selection of 'one adult within the household' is likely to be replaced by selection of the person who is the primary user of the mobile phone. In this sense, the correspondence between a person and her mobile telephone number creates an automatic selection mechanism that is straightforward and eliminates unwieldy survey introductions that often lead to refusals. Moreover, multiple unsuccessful calls that are made to a working mobile number will have a different meaning from that of the same number of attempts to reach an identified respondent in a household. It is also more likely that calls that are forwarded from a working mobile phone will result in contact with the respondent than calls that are forwarded from land-line numbers. In any case, the correspondence between a mobile phone number and a person suggests many of the modifications to disposition codes and survey processes that we outline in Section 3.

This shift in paradigms does not, however, universally translate into straightforward methods for designing samples of mobile phone users. Some countries, such as Finland, can use a national registry to capture both mobile and land-line telephone users. However, other countries, such as the USA, do not have such national registries and consequently are still searching for the best way to sample mobile phone numbers or combinations of land-line and mobile phone numbers. For example, some RDD sampling methodologies, like the Mitofsky-Waksberg method, lose their selection efficiencies when applied to mobile phone surveys whereas others, like list-assisted designs, cannot be used at all. Overcoverage in the mobile phone number frame introduces complex probabilities of selection that will have to be calculated for weighting adjustments, and so mobile phone surveys will need to determine in detail how many different numbers are associated with the respondent.

\subsection{Survey process in mobile phone surveys}

Owing to the correspondence between a mobile phone number and an individual, the mobile telephone can be considered a personal, private object such as a wrist-watch (Kuusela, 1998) and, as such, its use may have significant implications for the survey interview process. To have disposition codes that can track various aspects of mobile phone use will help researchers to evaluate the overall quality of the data and to judge the effectiveness of their collection strategies. The taxonomy of these disposition codes will be in part driven by the differences in possible outcomes of calls that are made to land-line and mobile phones. For example, technological differences between the phones lead to an increase in the types of outcomes that are possible. The variety of these outcomes for a call to an active mobile phone number is displayed in Fig. 2.

The oval shapes in the diagram indicate the outcomes that do not have counterparts in standard land-line surveys. Note that the diagram refers only to calls that are made to active numbers. Outcomes to inactive mobile and land-line phones (e.g. disconnected or non-working numbers that are usually flagged by such recorded messages as 'The number you have dialled is not a working number; please check the number and dial again') tend to be similar to one another and are not displayed in Fig. 2.

Among active numbers we see that mobile phones can be turned off. Practically this difference cannot be reflected in the disposition codes because the interviewer has no way of knowing that the phone is turned off. Thus only three outcomes are possible from the caller's perspective: 


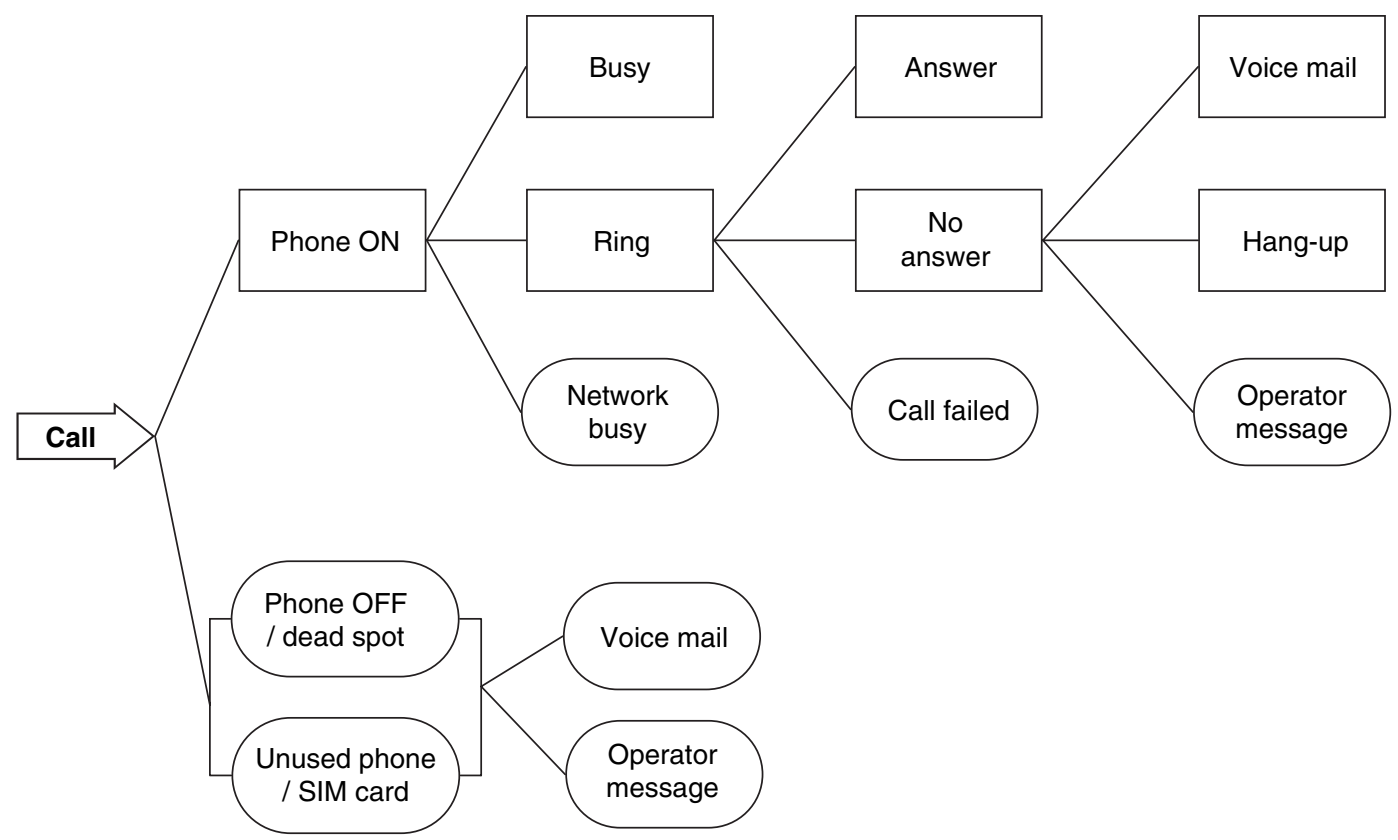

Fig. 2. Possible outcomes of a call to an active mobile phone number: $\circ$, new outcomes that can be encountered when calls are made to mobile phones, specifically

(a) a 'ring-no answer',

(b) either an 'answering machine message' in the case of a land-line phone or a 'voice mail message' in the case of a cellular phone or

(c) an 'operator message' saying that the customer is not reachable or may have the phone turned off.

Even when cell phone subscribers end an unwanted call by turning their phone off, callers cannot know for sure what has happened. Such an outcome may be coded by interviewers as a 'ring-no answer', as a 'hang-up', or even possibly as a 'technical problem'. In any case, there is no need for an additional code.

The ability to turn off a mobile phone may have an effect on the distribution of final outcomes, however. Although the ring tone of a fixed line telephone can be muted, thereby creating a situation that is similar to a cell phone that has been turned off, the practice is not very common. By comparison, a sizable percentage of cell phone subscribers keep their phones turned off for long periods. As a result mobile phone surveys will be likely to have more calls that end with an ambiguous outcome than traditional telephone surveys. Consequently, resolving these ambiguous cases will lead to more call attempts per case overall.

When the phone is on, many of the outcomes also resemble those of land-line phones, as Fig. 2 illustrates. However, there are instances when new codes are necessary. Indicating the failure of the mobile phone network to deliver the call, resulting in a 'network busy' message or a 'fast busy' signal, requires an additional code. The geographic portability of the mobile phone also creates the need for new dispositions. The personal nature of the mobile phone implies that the interview may take place in locations away from the respondent's home where unfavourable conditions lead to a higher percentage of partial interviews than in land-line surveys. Moreover, dropped calls due to technical problems also increase the percentage of partial interviews. 
Table 1. Examples of ambiguous operator messages, 2002-2003

\begin{tabular}{|c|c|}
\hline Company & Message \\
\hline AT\&T Wireless & We are unable to complete your call at this time \\
\hline Nebraska Wireless & $\begin{array}{l}\text { We are sorry: the call cannot be completed at this time; please check } \\
\text { the number and try again. }\end{array}$ \\
\hline Qwest Wireless & $\begin{array}{l}\text { The person you have called is not answering at this time; please try } \\
\text { again later }\end{array}$ \\
\hline Sprint & $\begin{array}{l}\text { The number or code that you have dialled is incorrect; please check } \\
\text { the number or code and dial again }\end{array}$ \\
\hline Cingular & Voice messaging service has not been activated \\
\hline Cingular & $\begin{array}{l}\text { The subscriber you have called is unavailable or has travelled outside } \\
\text { of the coverage area; please try your call again later }\end{array}$ \\
\hline Verizon Wireless & $\begin{array}{l}\text { The cellular phone you have called is turned off or out of the service } \\
\text { area; please try your call again }\end{array}$ \\
\hline Verizon Wireless & $\begin{array}{l}\text { Welcome to Verizon Wireless: the cellular customer you are calling } \\
\text { is not available at this time; please try your call again later }\end{array}$ \\
\hline Verizon Wireless & The customer you have called is not answering at this time \\
\hline T-Mobile & The subscriber you have called is not receiving calls at this time \\
\hline Alltel & $\begin{array}{l}\text { The wireless customer you are trying to reach in the Alltel network } \\
\text { is unavailable at this time; please try your call again later }\end{array}$ \\
\hline US Cellular & $\begin{array}{l}\text { The customer that you have called does not answer; please try your } \\
\text { call again later }\end{array}$ \\
\hline
\end{tabular}

Some countries, such as the USA, use a phone numbering system that includes a prefix that is indicative of geographical location. For local surveys, samples are often generated from these geographically relevant prefixes. Because mobile numbers have national attributes and are not as linked to location as fixed line numbers, it is possible that subscribers who live outside the target geographic area of a local survey may be inadvertently included. These kinds of subscriber should be classified as ineligible.

Operator messages for mobile phones are less specific and informative than the messages for land-line phones. Calls to mobile phones may result in one of many ambiguous operator messages. Results from a study that was carried out in the 402 area code of Nebraska (Callegaro, 2002a) and from the 2003 US cellular survey show the variety in these messages within and across companies. The messages in Table 1 do not clearly state whether the number is active or not, creating an unknown eligibility case. Ambiguous operator messages can be clarified by inquiring about their meanings from the companies themselves although the number of companies and the number of different messages make this prospect daunting. In some cases several possible scenarios may be described by the same message. For example, an AT\&T Wireless message states that 'we are unable to complete your call at this time'. The reasons for not completing the call may include network complications such as 'all circuits busy', or the customer is 'out of range' or the phone is 'not in service'. These options allow the possibility for either an eligible or ineligible outcome.

Callegaro (2004) also studied operator messages in Italy. In one experiment, by simulating the situation where an active number does not have voice mail and the phone itself is turned off, he could record the operator messages that resulted (which are listed in Table 2).

Apart from these issues, completion of surveys over mobile phones may be complicated by the costs that are incurred by subscribers themselves. For example, a person may refuse to participate in a survey because she does not want to pay the extra cost that is required to answer the interviewer's questions. This is particularly relevant in the USA where many mobile phone 
Table 2. Operator messages by Italian companies when calling active numbers with phone off and voice mail deactivated

\begin{tabular}{|ll|}
\hline Company & \multicolumn{1}{c|}{ Message } \\
Tre & $\begin{array}{l}\text { Three, this is a free message: the customer you called is not available at the moment } \\
\text { Free message from TIM: the person you are calling is, as of now, not reachable; do } \\
\text { you want to call again at the right time?; press } 5 \text { and an SMS will tell you when to } \\
\text { call back; the service 'call now' from TIM is free (the service 'call now' can be } \\
\text { disabled by the user but it is the default service when the voice mail has not been } \\
\text { activated) } \\
\text { Vodafone, free message: the telephone you are dialling might be switched off or is } \\
\text { out of reach; please try again later } \\
\text { Wind, the client you have called is not reachable at the moment: please call back } \\
\text { later }\end{array}$ \\
Wind & \\
\hline
\end{tabular}

owners pay for incoming calls, but it also has meaning in the European context (Robbins and Turner, 2002). It is common in Europe to incur roaming charges of half a euro or more per minute as a result of crossing national boundaries. Extra roaming charges apply as well in the USA when a mobile phone subscriber goes outside the provider's coverage area. These costs may also increase the number of partial or break-off interviews in mobile phone surveys.

The final aspect of the mobile phone landscape that may contribute to difficulties is caller identification technology. In addition to being more common on mobile phones than on land-line telephones, caller identification also works more effectively to screen calls. The fact that mobile phones generally show the names of callers (on the phone's display screen) only if they have been stored in the phone address book by the user makes even the appearance of a number rather than a name immediately suspect. Since it is highly unlikely that a potential respondent has stored the name and phone number of a survey research organization, a call from an interviewer will be received with scepticism. In some instances the word 'unknown' or 'unknown caller' appears in place of the number because of network technicalities. The way that caller identification works on a cellular telephone thus deprives the survey organization of one means, which is available on land-line phones, of legitimizing a call and thereby promoting participation (Callegaro et al., 2006). A study by Oftel (2003a) in the UK showed that cell phone owners do use caller identification for screening calls. Oftel found that $82 \%$ of mobile phone users have the capability to use caller identification on their mobile phone. Of those, $36 \%$ at least occasionally choose not to answer calls from an unrecognized or unidentified source. $7 \%$ never answer calls when neither a telephone number nor a caller's name is displayed, and 4\% never answer any calls from unrecognizable or unfamiliar sources. These data provide evidence that, when the number or name on the caller identification screen is unfamiliar, the call is likely to go unanswered.

Just as there are technological aspects of the mobile phone that make completing calls more difficult, there are other aspects that facilitate contact with a mobile phone subscriber including voice mail and text messaging. Voice mail is generally available through mobile phone plans and, where appropriate, we suggest that voice mail messages should always be left in mobile phone surveys to help to gain the co-operation of the respondent, especially when an incentive is offered. In addition to voice mail, a text message can inform respondents about the purposes of the survey. Although text messaging may be used as an invitation to participate in a phone survey (Steeh et al., 2006), it can also serve to remind prospective respondents during the calling period that the survey organization wishes to contact them (Buzzi et al., 2000). 


\section{Modifying the American Association for Public Opinion Research disposition codes}

The current codes in the latest edition of the AAPOR standard definitions (2006) have a hierarchical structure that is not visually emphasized in Table 1 of American Association for Public Opinion Research (2006), page 42. According to the AAPOR definitions, the first step in calculating a reliable response rate requires that each sample unit be properly classified as either eligible or ineligible. Eligible cases can also be subdivided into respondents, refusals, noncontacts and other non-interviews. In telephone surveys particularly, there is a sizable third category of numbers whose eligibility cannot be conclusively determined during a particular study. Our collective experiences in conducting actual surveys across two continents convinces us that the task of classifying outcomes into these categories is much more complicated in the case of mobile phones than it is for land-line telephones.

Not all of the suggestions that are presented in this section will have direct ties to the calculation of outcome rates according to the AAPOR formulae. Some will instead be relevant to improving the survey process by generating data that can lead to innovative and optimal call strategies for surveys of mobile phone numbers. Our interest in fostering responsive survey design (Groves and Heeringa, 2006) has caused us to stress the importance of the interim codes that we discuss below. Armed with meaningful interim codes, survey methodologists will gain the flexibility to change procedures during the survey field period in order to ensure maximum survey quality.

\subsection{Eligible, interview}

The first category in the AAPOR table seems straightforward and unlikely to need revision. However, the two factors to consider here are mode and location. To encourage participation and to accommodate variations in personal usage of mobile phones, interviewers in the 2003 US mobile phone survey offered to conduct the interview over a traditional telephone at a convenient time. When appropriate, interviewers also left messages on the first and third unanswered call attempts asking the potential respondent to call the survey organization to complete an interview. Because of these new procedures, it seemed worthwhile to create additional disposition codes for a completed interview. The revised classifications would designate a call completed

(a) on a mobile phone,

(a) on a land-line phone and

(a) by call-in from a mobile or land-line phone

(in the US survey experiment very few called in from either source, so we combine them here into one classification). Moreover, to judge the overall quality of the data, interviews might be subdivided into those completed on a mobile phone at home, in a public place or while driving. This information constitutes paradata (Couper and Lyberg, 2005) that can be used to study possible mode effects and the effects of location on the quality of the data. As shown in Table 3, the single AAPOR code for completed interview has become three. In Tables 3-5 and 8 later, additions, deletions and modifications to the AAPOR definitions will be italicized for easy reference.

\subsection{Eligible, non-interview}

There are three main reasons for eligible, non-interviews - refusals and break-offs, non-contacts and illness or language barriers. These outcomes are applicable to both mobile and land-line 
Table 3. Final disposition codes compared-interviews

\begin{tabular}{|c|c|c|}
\hline $\begin{array}{l}\text { AAPOR final disposition } \\
\text { codes-land-line only }\end{array}$ & Code & $\begin{array}{c}\text { Revised final disposition codes- } \\
\text { cell only }\end{array}$ \\
\hline 1. Interview & & 1. Interview \\
\hline Complete & $I$ & $\begin{array}{l}\text { Complete } \\
\text { On cell phone } \\
\text { On fixed line phone } \\
\text { By call-in }\end{array}$ \\
\hline Partial & $P$ & $\begin{array}{l}\text { Partial } \\
\text { Substantially complete; researcher } \\
\text { definition } \\
\text { Crucial questions only }\end{array}$ \\
\hline
\end{tabular}

telephones. However, there are differences in the subcategories for mobile phones. Table 4 displays how the standard eligible, non-interview, codes might be modified to provide additional information about non-respondents in a cellular telephone survey.

\subsubsection{Refusals and break-offs}

The AAPOR codes in the first column of Table 4 for traditional surveys distinguish between refusals and break-offs and within refusals between household level refusals and refusals by the person who is selected to be the respondent. Break-offs only occur after the chosen respondent has started the interview, but refusals can happen before selection of the respondent. In the case of mobile phone surveys, as we have mentioned, these distinctions may not matter as much since it seems highly unlikely that someone other than the primary user, who is the designated respondent, would answer a mobile phone. However, in a few instances someone else may answer and refuse. In these cases, mobile phone surveys need a disposition that is similar to the household level refusal in the AAPOR definitions, which we label refusal by 'someone besides respondent'. When the respondent is reached, the subcategories of refusal can be first-respondent refusal and second-respondent refusal, making it easy to check that all refusal conversions have been completed. Furthermore, call back efforts can be prioritized simply by looking at the number of refusals that have already been encountered for a given mobile phone number. In addition to refusals, it would be helpful to know whether or not a break-off occurred because of bad reception and excessive static, a situation that would apply only in the case of mobile phones.

\subsubsection{Non-contacts}

One significant feature of this type of non-interview in a traditional survey is that eligibility has been established either by talking to at least one person in the household or by receiving an informative message on an answering machine. Voice mail is the only mobile telephone equivalent since it is unlikely, in the USA at least, that anyone other than the primary user will answer a call to a mobile phone. Unfortunately, not every mobile or fixed line telephone has this service that helps survey practitioners to determine eligibility.

The AAPOR non-contact codes also suggest that a distinction should be made between temporary and final dispositions (American Association for Public Opinion Research (2006), pages 7-9). According to the standard definitions, 'temporary disposition codes should reflect the outcome of specific call attempts that occur before the case is finalized' (page 7). The temporary 
Table 4. Final disposition codes compared-eligible, non-interview

\begin{tabular}{|c|c|c|}
\hline $\begin{array}{l}\text { AAPOR final disposition codes- } \\
\text { land-line only }\end{array}$ & Code & $\begin{array}{l}\text { Revised final disposition codes- } \\
\text { cell only }\end{array}$ \\
\hline 2. Eligible, non-interview & \multirow{5}{*}{$R$} & 2. Eligible, non-interview \\
\hline Refusal and break-offs & & Refusal and break-offs \\
\hline Refusal & & Refusal \\
\hline Household level refusal & & Someone besides respondent \\
\hline Known respondent refusal & & $\begin{array}{l}\text { First-respondent refusal } \\
\text { Second-respondent refusal }\end{array}$ \\
\hline \multirow[t]{2}{*}{ Break-offs } & \multirow{5}{*}{$\mathrm{NC}$} & Break-offs \\
\hline & & $\begin{array}{l}\text { By respondent } \\
\text { Technical difficulties }\end{array}$ \\
\hline Respondent postponement $(>2)[\mathrm{I}]$ & & Respondent postponement $(>2)[\mathrm{I}]$ \\
\hline Non-contact & & Non-contact \\
\hline Respondent never available & & \\
\hline \multirow{4}{*}{$\begin{array}{l}\text { Telephone answering device (message } \\
\text { confirms residential household) [I] } \\
\text { Message left }[\mathrm{I}] \\
\text { No message left [I] }\end{array}$} & & $\begin{array}{l}\text { Voice mail (message confirms personal } \\
\text { use) [I] }\end{array}$ \\
\hline & & Message left $[\mathrm{I}]$ \\
\hline & & No message left $[\mathrm{I}]$ \\
\hline & & Text message delivered $[\mathrm{I}]$ \\
\hline Other & $O$ & Other \\
\hline \multicolumn{3}{|l|}{$\begin{array}{l}\text { Deceased respondent } \\
\text { Physically or mentally unable or }\end{array}$} \\
\hline & \\
\hline \multirow{2}{*}{\multicolumn{2}{|c|}{$\begin{array}{l}\text { Language } \\
\text { Household level language problem }\end{array}$}} & Language \\
\hline & & \\
\hline \multicolumn{2}{|l|}{ Respondent level language problem } & Respondent level language problem \\
\hline \multicolumn{2}{|l|}{$\begin{array}{l}\text { No interviewer available for needed } \\
\text { language }\end{array}$} & $\begin{array}{l}\text { No interviewer available for needed } \\
\text { language }\end{array}$ \\
\hline \multicolumn{3}{|l|}{ Respondent not available } \\
\hline \multirow{2}{*}{\multicolumn{2}{|c|}{ Respondent postponement $(<3)$}} & Respondent postponement $(<3)$ \\
\hline & & Poor environment for interview $[\mathrm{I}]$ \\
\hline Miscellaneous & & Static, poor reception $[\mathrm{I}]$ \\
\hline
\end{tabular}

codes that are suggested (page 8) do not describe the results of call attempts in enough detail to allow evaluation and adjustment of survey procedures during the interviewing period. We suggest instead that appropriate codes that are already among the final dispositions would provide better information. For example, all the codes that are listed under non-contact seem more properly classified as temporary or interim rather than as final dispositions. Interim codes, the terminology that we prefer, can appear again and again in call histories and provide information that can be used to gain co-operation in responsive survey designs. These kinds of codes are particularly important for surveys with large numbers of call attempts. Difficult-to-reach respondents, for example, may have a string of interim dispositions. To indicate the codes that may be considered interim, we place an ' $I$ ' in parentheses next to them in Tables 4, 5 and 8, later.

Although at the current time the existence of either voice mail or an answering machine message usually indicates an eligible number, this assumption is questionable for mobile telephones. Increasingly more children and adolescents have mobile phones, and the trend seems to be accelerating (Doxa, 2003; Oftel, 2003b). Thus other eligibility criteria, such as a minimum age, may not be as easily met for cell phones as for fixed line phones. In household surveys of the general population it is reasonable to assume that there is at least one person who is 18 years old who can serve as the respondent. This is not so with mobile phones that are tied more closely to 
individuals than to households. It may eventually be that interviewers need to speak with every potential mobile phone respondent, even those with voice mail, to verify their age eligibility.

When a mobile phone has voice mail, it is at least possible for the interviewer to leave a message to explain the survey request. Since there are few other opportunities to persuade respondents, voice mail messages may be left several times in mobile phone surveys to help to increase participation. Survey practitioners will want to know how many times a message has been left to evaluate the effectiveness of this procedure. Thus the subcategories in Table 4 under 'telephone answering device' are useful in mobile as well as fixed line telephone surveys. Only the words 'voice mail' should be substituted in the label for this subcategory.

Text messages are an additional means of communicating important study information to the potential respondent and of verifying the working status of a mobile phone. In particular, depending on the technology of the provider Web site, it is possible to have delivery of the text message confirmed by electronic mail. This kind of confirmation is almost certainly indicative of a working number (Steeh et al., 2006). In any case, having a text message delivered during the field period should count as a call attempt, and so we add 'text message delivered' to the dispositions for a mobile phone in Table 4.

'Respondent never available' implies that the AAPOR final code has been calculated from a series of unspecified outcomes, such as talking to the respondent who tells the interviewer 'I'm busy right now', or talking to someone else in the household who says that the respondent is not at home. The two situations, neither of which seems properly classified as a non-contact, can be differentiated by using interim codes. The first interim code changes the AAPOR wording to 'respondent not available' and moves the disposition into the 'other' category that we shall discuss next. The code now means that an interviewer spoke to someone in the household but could not actually talk to the chosen person. As we previously mentioned, this situation would probably not occur often in a mobile phone survey since mobile phones are consistently answered by the same individual. In calls to either a mobile or a land-line telephone another interim code would denote when a respondent replies with statements like 'I was on my way out when you called', 'I'm busy right now' or 'Call me back tomorrow'. Rather than classifying these kinds of outcomes as non-contacts, we propose to give them an interim code that indicates a 'respondent postponement'. If a respondent makes this kind of excuse more than twice during the field period - an example of a passive refusal, the final disposition would be coded as a refusal. Otherwise the final disposition would be 'respondent postponement' in the 'other' category. Thus, for both kinds of survey, we add the category 'respondent postponement' under 'refusals' when it occurs more than twice for the same person and under 'other' when it occurs less often. In this way we have replaced the vague definition 'respondent never available' with more descriptive codes and suggested a method for handling passive refusals. Of course, unavailability can also be indicated by ring, no answer and busy disposition codes, but, because these types of unavailability do not allow us to determine eligibility, we treat them in the next section.

\subsubsection{Other}

Table 4 shows that mobile phone surveys greatly reduce the number of situations that can be categorized as 'other' non-interviews. In both modes interviewers have contacted someone in the household, determined the respondent and found that an interview cannot be completed for one of the reasons specified. Of those which are listed in the first column of Table 4, three will occur so rarely that they seem inappropriate for mobile phone surveys - 'deceased respondent', 'physical disability or mental incompetence' and 'household level language problems'. We inserted the two respondent unavailability codes that we have just discussed and, under the miscellaneous 
subcategory, added two new codes that are appropriate for mobile phones - the interview cannot be conducted because reception is too poor to carry on a conversation regardless of the respondent's willingness and the interview cannot be conducted because the respondent is in an inappropriate situation such as driving a car or flying in a helicopter. In a survey that focused on the quality of mobile phone service in the USA that was carried out by the General Accounting Office, $30 \%$ of mobile phone users reported experiencing poor sound problems on $10 \%$ or more of their calls (General Accounting Office, 2003). Because survey contacts will no longer occur in a household context, we have every reason to expect that interviewers will have to call some individuals multiple times before they are in an environment that is conducive to a survey.

\subsection{Unknown eligibility, non-interview}

Unfortunately in telephone surveys there are sample cases that cannot be definitively classified as either eligible or ineligible. This complexity is as characteristic of calls that are made to mobile phones as it is of calls that are made to land-line telephone numbers. For example, some mobile phone numbers that are still in service do not have voice mail, are rarely used or are kept only in case of emergencies (e.g. being left in a car). In Europe, where prepaid service is common, companies keep numbers active for at least 6 months after the last payment. Although the prepaid subscriber can still receive phone calls for free during the 6-month grace period, it is likely that a survey interviewer would have a difficult time making contact. The indeterminacy of prepaid status has led the National Authority of Telecommunications in both France and Germany to calculate penetration rates excluding prepaid users who, though registered, did not generate revenues in the last 6 months or more (Autorité de Régulation des Télécommunications, 2004; Regulatory Authority for Telecommunications and Posts, 2004). Finally third-generation mobile phones that are equipped with universal mobile telecommunications system technology that enables users to surf the Internet at broadband speed can operate with SIM cards that are devoted solely to accessing the Internet.

Table 5. Final disposition codes compared—unknown eligibility, non-interview

\begin{tabular}{|c|c|c|}
\hline Final disposition codes - land-line only & Code & Final disposition codes - cell only \\
\hline $\begin{array}{l}\text { 3. Unknown eligibility, non-interview [I] } \\
\text { Unknown if housing unit }[\mathrm{I}]\end{array}$ & HE & 3. Unknown eligibility, non-interview [I] \\
\hline Not attempted or worked & & Not attempted or worked [I] \\
\hline Always busy & & $\begin{array}{l}\text { Busy }[\mathrm{I}] \\
\text { Network busy }[\mathrm{I}]\end{array}$ \\
\hline No answer [I] & & $\begin{array}{l}\text { No answer }[\mathrm{I}] \\
\text { Unclassifiable operator message }[\mathrm{I}]\end{array}$ \\
\hline $\begin{array}{l}\text { Telephone answering device (do not } \\
\text { know if housing unit) }[\mathrm{I}]\end{array}$ & & Voice mail (cannot tell if personal) [I] \\
\hline $\begin{array}{l}\text { Telecommunications, technological } \\
\text { barriers (e.g. call-blocking) [I] }\end{array}$ & & $\begin{array}{l}\text { Telecommunications, technological } \\
\text { barriers }[\mathrm{I}]\end{array}$ \\
\hline Technical phone problems & & $\begin{array}{l}\text { Technical phone problems }[\mathrm{I}] \\
\text { Text message sent }[\mathrm{I}]\end{array}$ \\
\hline $\begin{array}{l}\text { Housing unit, unknown if eligible } \\
\text { respondent [I] }\end{array}$ & & \\
\hline $\begin{array}{l}\text { No screener completed [I] } \\
\text { Other [I] }\end{array}$ & & No screener completed [I] \\
\hline Immediate hang-up [I] & & Immediate hang-up $[\mathrm{I}]$ \\
\hline Temporarily out of service $[\mathrm{I}]$ & & Temporarily out of service [I] \\
\hline Fax/data line [I] & & Fax/data line [I] \\
\hline
\end{tabular}


Table 6. Percentage of 'no answer' dispositions by call attempt and type of survey $\dagger$

\begin{tabular}{|c|c|c|c|c|c|c|c|c|c|c|c|}
\hline \multirow[t]{2}{*}{ Call } & \multicolumn{4}{|c|}{ Results for cell phones } & \multicolumn{4}{|c|}{ Results for fixed line phones } & \multicolumn{3}{|c|}{ Difference } \\
\hline & $\begin{array}{l}\text { Total } N \\
\text { eligible }\end{array}$ & $\begin{array}{c}\% \\
\text { voice } \\
\text { mail }\end{array}$ & $\begin{array}{l}\% \\
\text { busy }\end{array}$ & $\begin{array}{l}\% \text { no } \\
\text { answer }\end{array}$ & $\begin{array}{l}\text { Total } N \\
\text { eligible }\end{array}$ & $\begin{array}{c}\% \\
\text { answering } \\
\text { machine }\end{array}$ & $\begin{array}{c}\% \\
\text { busy }\end{array}$ & $\begin{array}{l}\% \text { no } \\
\text { answer }\end{array}$ & $\begin{array}{c}\% \text { voice } \\
\text { mail or } \\
\text { answering } \\
\text { machine }\end{array}$ & $\begin{array}{l}\% \\
\text { busy }\end{array}$ & $\begin{array}{l}\% \text { no } \\
\text { answer }\end{array}$ \\
\hline 1 & 3945 & 42.2 & 2.0 & 21.4 & 1517 & 31.5 & 4.5 & 13.3 & 10.6 & -2.5 & 8.1 \\
\hline 2 & 3787 & 42.1 & 1.8 & 23.2 & 1358 & 35.2 & 4.6 & 17.2 & 6.9 & -2.7 & 6.0 \\
\hline 3 & 3464 & 43.2 & 1.6 & 24.2 & 1204 & 38.4 & 5.1 & 19.9 & 4.8 & -3.4 & 4.3 \\
\hline 4 & 3132 & 45.2 & 1.3 & 26.7 & 1005 & 41.3 & 5.9 & 20.4 & 3.9 & -4.6 & 6.3 \\
\hline 5 & 2835 & 46.1 & 1.1 & 27.7 & 839 & 47.9 & 4.4 & 21.9 & -1.8 & -3.4 & 5.7 \\
\hline 6 & 2589 & 44.8 & 0.8 & 28.4 & 743 & 46.6 & 5.2 & 23.0 & -1.8 & -4.4 & 5.4 \\
\hline 7 & 2305 & 45.6 & 0.8 & 29.4 & 661 & 46.0 & 5.3 & 24.4 & -0.4 & -4.5 & 5.1 \\
\hline 8 & 2108 & 46.0 & 1.0 & 31.1 & 593 & 46.9 & 4.2 & 25.0 & -0.9 & -3.2 & 6.2 \\
\hline 9 & 1950 & 48.8 & 0.9 & 31.5 & 527 & 50.3 & 6.6 & 26.6 & -1.5 & -5.7 & 4.9 \\
\hline 10 & 1833 & 47.7 & 0.6 & 32.5 & 493 & 48.5 & 3.2 & 29.0 & -0.8 & -2.6 & 3.5 \\
\hline
\end{tabular}

†Source: 2003 US National Cellular Survey and 2003 US National Fixed Line Survey. For this comparison all sample telephone numbers that were classified as clearly ineligible were excluded from the analysis since the much larger proportion of ineligible numbers in the cell phone sample (with none of the numbers screened out in advance) would have seriously distorted the percentages.

Table 5 shows that the AAPOR codes define two classes of unknown eligibility: 'unknown if housing unit' and 'unknown if an eligible respondent lives in the unit'. With mobile phone surveys the distinction does not apply since the household is no longer a stage in the sampling process. For this reason, we eliminate all dispositions that refer to the household level. The remaining codes have the same function as the interim codes that were defined during our discussion of Table 4 and are so designated in Table 5.

Most probably, there will be many cases when every call attempt, including the last, ends with one of these interim codes. In a survey with many call-backs, however, it would be rare to find an instance when all calls ended with the same interim code. For this reason the 'always busy' disposition in the AAPOR definitions is not as likely in a mobile phone as in a fixed line survey. Roy and Vanheuverzwyn (2002) found in a study on mobile phones in France that only 44 out of 9840 numbers $(0.44 \%)$ could be classified as always busy during the field period. Table 6 , which lists the percentages of all eligible and unknown eligible sample units that fell into several of these interim categories during the first 10 call attempts for the two US surveys that are covered in this paper, confirms the point. From the differences that are displayed in the last three columns of Table 6 , we can see that the percentages of busy outcomes in a cellular survey are uniformly lower than the same percentages for a land-line survey. In contrast, network busy or fast busy signals appear to be much more prevalent in cellular telephone surveys than we would expect from conventional RDD studies. Thus we recommend dropping the word 'always' from the 'busy' disposition code and adding a new code to indicate a 'network busy' signal.

The 'no answer' disposition refers to calls that ring without being answered or are answered by a recording that leaves the eligibility status of the number in doubt. As Table 6 indicates, the no answer code is more common in mobile phone surveys than in land-line telephone surveys especially at the beginning of the field period. Although the difference attenuates as the number of calls increases, each attempt shows that a larger percentage of calls were classified as no answer in the mobile phone survey. This situation happens for a reason that we have already noted. Many subscribers in the USA use their cellular phones only periodically, leaving them 
turned off most of the time. Thus it is risky to assume, as we do sometimes in fixed line surveys, that a long series of no answer dispositions indicates a non-working number. Unlike always busy, always no answer may be a viable disposition for cellular surveys, though there were few instances of this pattern in the US 2003 cellular survey.

Although the data in Table 6 for the no answer disposition also include ambiguous operator messages, it may be preferable in future surveys to distinguish between the two dispositions no answer and unclear operator message. The latter disposition would be more useful for mobile phones than for land-lines and would be assigned when an interviewer cannot determine the eligibility of the phone number from the message content. It might be that the number that is reached is rarely used or just that the phone is off, as shown in Fig. 2. Both in Europe and in the USA, a vague operator message should never be treated automatically as ineligible.

We also suggest the addition of 'immediate hang-up' as a code for both types of survey because again an immediate hang-up offers no means for establishing eligibility. Although we expected more immediate hang-ups in the cellular survey than in the land-line survey, we found to our surprise that they were four times more likely in the 2003 US land-line survey (13\% versus $3.1 \%$ at the first call attempt). By the 10th attempt the difference in the number of hang-ups for land-line and cellular numbers was smaller but in the same direction, indicating fewer hang-ups on calls that are made to mobile phone numbers. In the case of mobile phones, the immediate hang-up disposition may reflect a dropped call or network malfunction, so these dispositions may not signal refusals as we might logically assume.

Finally, in contrast with the AAPOR definitions, we place 'fax/dataline' in the unknown eligibility category because for most mobile phones, as for many fixed line telephones, a fax or data signal does not mean that the number is dedicated to either or both of these purposes and is never used for voice calls. The two instances in which a 'fax/dataline' disposition could signal an ineligible sample unit will be discussed below.

The true difficulty with the unknown eligibility category of non-response lies in the multiplicity of interim outcomes that can occur across call attempts. How should the proper final disposition be determined? The 'Standard definitions statement' (American Association for Public Opinion Research (2006), pages 8-9) gives several unfolding alternatives. First, choose the one that is valid on a 'status day' that is determined by the researcher. If that is not possible, choose the outcome of the last attempt involving human contact, or, if there has been no human contact, choose the code that provides the most information about the case. Our solution is simpler. Call records that mix these interim codes across a large number of attempts should finally be classified only by the overall category unknown eligibility.

However, the call history for a particular sample unit may mix unknown eligibility codes with a few that indicate eligibility. In this specific case, the final disposition is determined by the eligibility codes. Precedence should be given to codes that indicate that an eligible respondent has been selected and then to codes that show that the sample unit is eligible even though a respondent has not been chosen. Most of these cases will be classified as non-contacts. Table 7 gives several different call histories and indicates for each the appropriate final disposition by using this decision method. Additionally, the prevalence and pattern of these interim codes both across call attempts and across cases provides information for implementing responsive survey designs.

The size of the unknown eligibility category negatively affects the response rate. As a result of studies showing that a large percentage of land-line numbers are non-working (Brick et al., 2002; Shapiro et al., 1995), a correction factor $e$ was allowed first by the Council of American Survey Reseach Organizations guidelines and then by the AAPOR standards. $e$ is the likely proportion of eligible cases among those of unknown eligibility and can be estimated in several ways (Smith, 2003). This percentage has an effect on AAPOR rates RR3, RR4, REF2 and CON2. From our 
Table 7. Examples of fitting final disposition codes to a series of interim codes

\begin{tabular}{|c|c|c|c|c|c|}
\hline Call attempt & Case 1 & Case 2 & Case 3 & Case 4 & Case 5 \\
\hline \multicolumn{6}{|l|}{ Interim codes } \\
\hline 1 & No answer & No answer & No answer & No answer & No answer \\
\hline 2 & Busy & Busy & Busy & Busy & Busy \\
\hline 3 & No answer & No answer & No answer & No answer & No answer \\
\hline 4 & $\begin{array}{l}\text { Fax or data } \\
\text { line }\end{array}$ & $\begin{array}{l}\text { Text message } \\
\text { delivered }\end{array}$ & $\begin{array}{l}\text { Text message } \\
\text { delivered }\end{array}$ & $\begin{array}{l}\text { Text message } \\
\text { delivered }\end{array}$ & $\begin{array}{l}\text { Text message } \\
\text { sent }\end{array}$ \\
\hline 5 & Busy & Busy & Busy & Busy & Busy \\
\hline 6 & No answer & No answer & No answer & No answer & No answer \\
\hline 7 & $\begin{array}{l}\text { Fax or data } \\
\text { line }\end{array}$ & $\begin{array}{l}\text { Refusal by } \\
\text { someone else }\end{array}$ & $\begin{array}{l}\text { Refusal by } \\
\text { someone else }\end{array}$ & No answer & No answer \\
\hline 8 & No answer & No answer & No answer & No answer & No answer \\
\hline 9 & No answer & No answer & No answer & No answer & No answer \\
\hline 10 & $\begin{array}{l}\text { Fax or data } \\
\text { line }\end{array}$ & $\begin{array}{l}\text { Respondent } \\
\text { postponement } \\
<3\end{array}$ & Busy & Busy & Busy \\
\hline 11 & No answer & No answer & No answer & No answer & No answer \\
\hline 12 & No answer & No answer & No answer & No answer & No answer \\
\hline \multicolumn{6}{|l|}{ Final code } \\
\hline & $\begin{array}{l}\text { Dedicated fax } \\
\text { or data line }\end{array}$ & $\begin{array}{l}\text { Respondent } \\
\text { postponement }\end{array}$ & $\begin{array}{l}\text { Respondent } \\
\text { not available }\end{array}$ & Non-contact & $\begin{array}{l}\text { Unknown } \\
\text { eligibility }\end{array}$ \\
\hline
\end{tabular}

experience it seems that mobile phone numbers of unknown eligibility are more likely to be working than similar land-line numbers. This is due to several factors: prepaid cell phones are probably turned off most of the time; many owners use their cell phones only for emergencies; owners have multiple SIM cards; operator messages are ambiguous in contrast with land-line operator messages. Consequently, $e$ will not be as effective an adjustment in outcome rate calculations as in fixed line surveys. Thus for mobile phones the criteria for eligibility need to be expanded as a way to reduce the size of the unknown eligibility category instead of using $e$ or in addition to using $e$. For example, a call history that is made up only of no answer dispositions could signal an extra SIM card lying unused in a bureau drawer. Practically this mobile number is not accessible and should reasonably be removed from the base of the response rate. This relaxation in the criteria for eligibility can only take place if a large number of call attempts is allowed and the field period is lengthy. In addition, if mobile phone companies would provide a list of operator messages and a description of what each means, numbers could be more easily classified as not eligible. A few practices that are unique to specific mobile phone companies would help if they were widespread. For example, in Italy, the company TIM offers the 'call now' service (see Table 2). If the mobile phone called is off or out of the area and voice mail is disabled, the company offers the option of pressing 5 to receive an automatic text message telling the caller that the client has switched on the phone. If during the field period no such message is received (provided that the phone that is used in the call centre was capable of receiving text messages), it is very likely that the researcher called an unused SIM card. This kind of outcome can be classified as ineligible, a status which we take up below.

\subsection{Not eligible}

Finally we come to the 'not eligible' dispositions. Cases with these final dispositions are not directly used in the computation of any of the AAPOR-endorsed outcome rates, but it is important to classify these numbers correctly since they determine the size of the base that is used in the 
Table 8. Final disposition codes compared—not eligible, non-sample

\begin{tabular}{|ll|}
\hline Final disposition codes_land-line only & Final disposition codes_cell phone only \\
\hline 4. Not eligible & \\
Out of sample & 4. Not eligible \\
Dedicated fax or dataline & Out of sample \\
Non-working or disconnected number & Dedicated fax or dataline \\
Non working [I] & Non-working or disconnected number \\
Disconnected [I] & Non-working [I] \\
Temporarily out of service & Disconnected [I] \\
Special technological circumstances & Special technological circumstances \\
Number changed & Number changed \\
Cell phone & Land-line phone \\
Call forwarding & \\
Residence to residence & \\
Non-residence to residence & \\
Pagers [I] & Pagers [I] \\
Non-residence & Non-residence \\
Business, or Government office or & Business, or Government office or \\
other organization [I] & other organization [I] \\
Institution [I] & Institution [I] \\
Group quarters [I] & Group quarters [I] \\
No eligible respondent & No eligible respondent \\
Quota filled & Quota filled \\
& Phone or SIM card not used \\
\end{tabular}

calculations. However, the presence of many ineligible numbers, as happens in current mobile phone surveys, lengthens the field period and increases the costs of the survey. The criteria for declaring a case ineligible according to the AAPOR standard definitions are listed in Table 8.

The first code, 'out of sample', refers to a sample unit that is outside the physical boundaries of a study. This situation has, in the past, been more relevant to fixed line surveys of local areas rather than to national surveys. For example, in many European countries and Australia the mobile phone number is formed from a prefix of 2-4 digits and a suffix of $6-8$ digits. Because the prefix does not pin-point the precise geographical location of a sampling unit, local surveys are seldom conducted on mobile phones in those countries (Callegaro, 2002b; Roy and Vanheuverzwyn, 2002). In the USA mobile phone numbers tend to be assigned on the basis of geographical areas, but this association is weakening considerably as owners move from one location to another but keep their same number. Thus when the allocation system is nationwide, as in Europe and increasingly in the USA, the out of sample code has little meaning. We suggest retaining it, however, for those times when it might apply - e.g. during a local study in the USA.

In accordance with our previous discussion, we suggest that the 'fax/dataline' disposition be defined here as 'dedicated fax/dataline'. There are only two ways to know that a number is dedicated to fax or data transmission. In the first, an operator message states that the phone is dedicated to facsimiles or computers. A few companies in the USA, like Verizon Wireless, allow customers to receive facsimile messages through voice mail, but this option is not advertised. The case is different in Europe where global system for mobile communications technology allows companies to assign mobile phone numbers solely for facsimile transmission. The caller hears a message saying that the number is for facsimiles and then a facsimile service tone. Numbers of this type are definitely not eligible.

In the absence of such a clear indicator, ineligible status may be signalled by a pattern of interim outcomes that is consistent with dedicated fax or data use. These kinds of patterns are 
relatively easy to recognize when the survey mode is a land-line telephone. However, mobile phones in Europe and the USA serve many functions, including connecting to the Internet, and so these patterns are much more difficult to identify. In the USA, from April 2004, 25\% of all mobile telephone subscribers were casual data users, most of whom used text messaging and some of whom used picture mail, downloaded ring tones, or surfed the Web (Federal Communication Commission, 2004). With the exception of facsimiles, it is unlikely that a mobile phone would be dedicated solely to these purposes even in Europe. Again unlike facsimile messages no unique signal indicates that the wireless phone is being used to surf the Web or to send and receive electronic mail. Someone calling a mobile phone that is transmitting or receiving data may receive any one of several responses depending on the technology that is available and the specific provider. Among the possibilities are a ring tone (as happens with call waiting), a busy signal, a company message, voice mail or call forwarding. One possible pattern that suggests dedicated use is shown as case 1 in Table 7 . On three occasions, the interviewer identified a facsimile message signal, and none of the other call attempts produced contact with either voice mail or a person. Thus it is very likely that this mobile phone-or any land-line phone with the same call history - is dedicated to facsimile and data transmission.

The 'temporarily out of service' disposition is also appropriate for both kinds of telephone surveys but belongs in the unknown eligibility rather than the not eligible category. A series of these codes across multiple call attempts would suggest that the final disposition should be 'disconnected' just as a series of fax dispositions indicates a 'dedicated fax line'. Examples of the operator messages in the USA that identify these temporarily disconnected numbers include 'the PCS telephone number you have dialled is temporarily not in service' and 'The subscriber you have dialled is not in service - if you feel you have received this message in error — please hang up and try your call again later'.

Only two dispositions under the heading 'special technological circumstances' need modification. In the US 2003 traditional fixed line survey, the 'cell phone' disposition indicated that the number belonged to a mobile phone and was, therefore, not eligible. Since then, number portability in the USA, which allows subscribers to keep a telephone number when changing cell phone providers or when changing service from one type to another (e.g. from land-line to mobile), has muddied the waters considerably. In Europe mobile phone number portability is possible for the majority of countries (Electronic Communications Committee, 2005). Although software is being developed that will eventually identify ported numbers, it has not yet been perfected. In addition, the thrust of telephone surveys will be away from pure surveys, either fixed line or mobile, and towards a combination of the two modes. When samples that mix mobile and fixed line numbers become routine, this code can be eliminated altogether. Until then, however, we recommend the retention of this disposition so that, in pure surveys, numbers that belong to the other mode can be properly excluded as ineligible. However, we do recommend that 'call forwarding' be dropped from the 'not eligible' codes for mobile phones. One of the prominent features of mobile phones is their omnipresence. Subscribers tend to carry their phones with them everywhere. As a result, call forwarding will be an infrequent result in mobile phone surveys.

Although the other special technological circumstance is applicable to both modes, we remark that 'number changed' in the case of mobile phones is much more difficult to interpret owing to the lack of uniform notification messages across companies. For example, the message may simply state 'The number you have reached [number] has been changed. The new number is [number]'. However, many cellular phone companies in the USA do not issue number change messages at all. They only issue an automated message that a number has been disconnected or is non-working if an account has been terminated. In any case the messages may not distinguish between a change that occurs because the subscriber initiated the change or because 
the telephone company renumbered area codes, which is a crucial distinction for eligibility. It is also possible that the final disposition code 'number changed' will not be as common in the future since, in the era of number portability, mobile phone subscribers may tend to keep their numbers over longer periods than land-line subscribers.

We comment that 'no eligible respondent' is a more frequent disposition for cellular surveys than for traditional land-line surveys. With the increasing mobile phone penetration rate, increasingly more children are becoming primary mobile phone users. In 2002 in Italy $2 \%$ of children who were 5-6 years old owned a cellular phone. The percentage rises linearly to $68 \%$ by age 13 years (Doxa, 2003). In August 2003, 89\% of those aged 15-24 years owned a cellular phone in the UK (Oftel, 2003b). Hence when a minimum age for eligibility is specified, any cellular phone number that is associated with a primary user who is below that age would be classified as ineligible.

Finally we add an ineligibility category for those cases that we suspect indicate an unused SIM card or a mobile phone, as would be the case for those phones lying unused in the glove compartment of a subscriber's car, for example. Before a case could be classified as ineligible for this reason, its call history should be composed of 'ring, no answer' dispositions across at least $10-15$ consecutive call attempts.

Table 8 shows that many of the ineligibility codes are interim rather than final codes. The practice of requiring two call attempts before classifying a case as ineligible complicates assigning final dispositions. For example, non-working or disconnected status is clearly indicated when two consecutive calls terminate with an operator message that states that the number has been disconnected. Otherwise, the call history becomes confusing, especially when codes from all three categories - eligible, unknown eligibility and ineligible - are present and the number of call attempts is large. The histories of calls in mobile phone surveys employing RDD samples seem especially prone to such unconventional patterns and, the longer the field period, the more likely they are to occur. Although we recognize its effect on response rate calculations, the only practical solution to this problem is to assign cases with call histories that contain all three types of interim code to the unknown eligibility category.

\section{New disposition codes in practice: three survey examples}

Although our revised set of disposition codes was developed after the surveys that we now review had been completed, we thought that it would be instructive to calculate the AAPOR-approved outcome rates for each as nearly as possible on the basis of the definitions that we have outlined. Thus we illustrate that the revised codes have an international applicability. Two surveys were conducted only on mobile phones, but the third study went a step further by including calls to both fixed line and mobile numbers. Our examples cover a broad range of mobile phone systems with varying rates of national penetration. They include Finland-a nation with the highest rate of mobile-phone-only households in the world, Slovenia - a nation that mirrors the penetration rates and mobile-phone-only household percentages of many European nations, and the USA, where the conditions for owning mobile phones make conducting surveys using them especially difficult. The surveys vary in the number of interviews that were completed and in the sponsoring organization.

The Finnish study is 1 month, February 2004, of the on-going Consumer Barometer Survey that was conducted by Statistics Finland and has a sample size of 2200 individuals who were selected from the Finnish Population Registry. Because the registry lists addresses, all sample units were sent an advance letter even when the person was to be contacted by mobile phone. During this particular month, $52 \%$ of the interviews were conducted over a mobile phone. In 
Table 9. Disposition categories by country

\begin{tabular}{|lccc|}
\hline Disposition category & USA (\%) & Slovenia (\%) & Finland (\%) \\
\hline Interview & 10 & 27 & 79 \\
Non-interview, eligible & 35 & 29 & 13 \\
Non-interview, & 13 & 13 & 8 \\
$\quad$ eligibility unknown & 42 & 32 & 0 \\
Not eligible & & & \\
\hline
\end{tabular}

Finland practically all working-age people (and teenagers) have a mobile phone and nearly all regard it as their primary phone even if they have a fixed line as well. People are used to participating in long conversations over mobile phones, and there are practically no prepaid subscriptions. This system works because all phones numbers in Finland (both fixed and mobile) are listed in a database that can be accessed via the Internet.

The other two studies were RDD surveys which were sponsored by academic organizations in 2003 and had sample sizes of 550 in Slovenia (Vehovar et al., 2004) and 7999 in the USA. The very large sample size in the USA was necessary to obtain 800 interviews given the working rate for mobile phone numbers in the US telephone system at the time of the survey. The sample unit in each case was a mobile phone number rather than an individual as in Finland. Table 9 lists the percentage of the sample in each of the four broad disposition categories. The differences are striking. For instance, drawing a sample from a population registry, as in Finland, virtually eliminates not eligible cases.

The variation in the not eligible rates between the other two surveys undoubtedly reflects differences in the sample frames and variations in the overall penetration rates of mobile phones across the two countries. In Slovenia the sample frame was limited to the largest mobile company Mobitel (which has $80 \%$ market share). The sample frame for the US study covered all mobile phone providers and all area codes with exchanges solely devoted to mobile phone numbers. The differences in the interview percentages are more difficult to explain. The called party pays provisions of cell phone ownership in the USA undoubtedly affect the willingness of subscribers to accept calls from strangers. The exceedingly high interview rate for the Finnish Consumer Barometer is at least partly the result of the advance letters and official sponsorship by the Government. We speculate that it is also partly due to low numbers of prepaid subscriptions, extensive listing of mobile phone numbers in a publicly accessible database and a greater tendency to treat mobile phones as part of daily life.

As a final step, we calculate the various outcome rates that are suggested by the AAPOR standards for each survey. We follow the formulae that contain the largest number of operands and thus present the most favourable outcomes (American Association for Public Opinion Research (2006), pages 32-36). Again in Table 10 we see the same pattern of results as appeared in Table 9-the most favourable outcome rates in Finland with the least favourable in the USA. The Finnish example establishes that surveys including mobile phones can be quite successful, exceeding by far the outcome rates of most standard telephone surveys in the USA at the present time.

\section{Conclusion}

The experiences that three different countries have had in interviewing adults over mobile phones point in the same direction. The standard definitions that are used for conventional land-line 
Table 10. Outcome rates by survey

\begin{tabular}{|lccc|}
\hline AAPOR formula & USA $(\%)$ & Slovenia $(\%)$ & Finland $(\%)$ \\
\hline RR4\$ & 21 & 43 & 86 \\
COOP2§ & 31 & 54 & 90 \\
REF2\$§ & 46 & 34 & 8 \\
CON2* & 68 & 80 & 95 \\
\hline
\end{tabular}

$\dagger$ In the following formulae, $I$ denotes completed interviews, $P$ denotes partial interviews, $R$ denotes refusals, NC denotes no contact, $O$ denotes other, HE denotes unknown eligibility and $e$ is the estimated proportion of cases of unknown eligibility that are eligible. These categories are labelled in Tables $3-5$ and 8.

$\dagger \mathrm{RR} 4=(I+P) /(I+P+R+N C+O+e \mathrm{HE})$.

$\S \mathrm{COOP} 2=(I+P) /(I+P+R+O)$.

$\S \S \mathrm{REF} 2=R /(I+P+R+N C+O+e \mathrm{HE})$.

${ }^{*} \mathrm{CON} 2=I+P+R+O /(I+P+R+N C+O+e \mathrm{HE})$.

RDD surveys cannot be simply transferred to RDD surveys that are conducted over mobile phones. Too many survey conditions are different to warrant our treating mobile phones as just another telephony device. In this work we have described the major changes to current AAPOR final disposition codes that seem desirable for researchers to calculate meaningful outcome rates for mobile phone surveys as well as to track and monitor the survey process more efficiently. We concluded that some codes do not apply anymore, that others have different meanings and that new codes which are specifically tailored to mobile phones must be added. We also took into account how mobile phones operate in an international context so that our revisions would be broadly relevant.

Compared with fixed line telephones, the mobile phone system lacks standardization. Across providers, operator messages about similar situations vary widely and are often too vague for interviewers to classify unambiguously. In addition, the call records across single cases contain more diverse dispositions than the call records in a fixed line telephone survey. Thus dialling the same mobile phone number repeatedly may yield a mix of eligible, undetermined and even sometimes ineligible outcomes. This considerably complicates the process of assigning one final disposition. Our recommendation is simply to count all cases with such confusing call histories, made up only of interim codes, as of unknown eligibility, especially when two ineligibility dispositions are widely separated in the call history.

Additionally in a standard RDD telephone survey we expect that, the longer the field period, the fewer the unknown eligibility cases that will remain and the better we shall be able to assign a final disposition code. In a mobile phone survey this is not necessarily so. The current transience of mobile numbers, in the USA at any rate, means that over a field period of months many numbers may go through several statuses that include not in service, prepaid and disconnected as well as working. Thus long field periods lead to the complicated call histories that we have just discussed and that make it very difficult to assign a final disposition code.

We have identified many codes that can best be treated as interim, and we have created procedures for deriving final dispositions from these interim codes that can generally be implemented through processing algorithms in computer-assisted telephone interviewing systems. The 'Behavior risk factor surveillance system' and the 'Adult tobacco survey', which are both conducted by the Centers for Disease Control and Prevention in the USA, already employ these kinds of algorithm in assigning final dispositions. Using the modifications to the AAPOR codes 
that we suggest will allow researchers to adapt calling schedules more easily throughout the field period and to plan strategies that increase co-operation.

The revised and amended set of codes that we have proposed in this paper may have an even wider application than we have mentioned. Technology is moving the base of survey sampling away from households to individuals, and it seems likely that the telephone survey of the future may resemble a combination of the methods that were used in Finland, Slovenia and the USA. Because sometime soon surveys will mix calls to fixed line telephones with calls to mobile phones, methods will need to accommodate both modes. In the future self-administered mobile phone surveys and voice Internet protocol surveys will also be part of the mix. The disposition codes that we have developed in this paper will fit these multimode surveys as well as they fit surveys that are carried out solely by mobile phones.

Although ours is only a first effort to adapt current AAPOR disposition codes to a changing telephony environment, we have proceeded on the basis of concrete evidence that was gained from close analysis of three survey projects. We have noted a startling difference in outcome rates across the three with Finland, where conditions are the most favourable to mobile phone technology, leading the way, Slovenia in the middle and the USA lagging behind. This helps us to understand the potential of future telephone surveys and puts all our current efforts on a larger stage.

\section{Acknowledgement}

The US project was funded by the National Science Foundation under grant SES-0207843.

\section{References}

American Association for Public Opinion Research (1998) Standard Definitions: Final Dispositions of Case Codes and Outcome Rates for Surveys. Lenexa: American Association for Public Opinion Research.

American Association for Public Opinion Research (2000) Standard Definitions: Final Dispositions of Case Codes and Outcome Rates for Surveys, 2nd edn. Lenexa: American Association for Public Opinion Research.

American Association for Public Opinion Research (2005) Standard Definitions: Final Dispositions of Case Codes and Outcome Rates for Surveys, on-line edn 3.1. Lenexa: American Association for Public Opinion Research.

American Association for Public Opinion Research (2006) Standard Definitions: Final Dispositions of Case Codes and Outcome Rates for Surveys, 4th edn. Lenexa: American Association for Public Opinion Research.

American Statistical Association (1974) Report on the ASA Conference on Surveys of Human Populations. Am. Statistn, 28, 30-34.

Autorité de Régulation des Télécommunications (2004) L'observatoire des Mobiles: Données Chiffrées au: 31 Décembre 2003. Paris: Autorité de Régulation des Télécommunications.

Beck, F., Legleye, S. and Peretti-Watel, P. (2005) Aux abonnes absents: liste rouge et telephone portable dans les enquetes en population générale sur les drogues. Bull. Methodol. Sociol., 86, 5-29.

Brick, M. J., Montaquila, J. and Scheuren, F. (2002) Estimating residency rates for undetermined telephone numbers. Publ. Opin. Q., 66, 18-39.

Buzzi, C., Callegaro, M., Schizzerotto, A. and Vezzoni, C. (2000) Studio o Lavoro?: le Scelte Formative ed Occupazionali dei Maturi Trentini. Trento: Rettorato.

Callegaro, M. (2002a) Building the frame for mobile phone surveys: telephone sampling designs for cellular phone surveys: a feasibility study in the 402 area code. Manuscript. University of Nebraska, Lincoln. Unpublished.

Callegaro, M. (2002b) The cellular phone situation in Italy: coverage, frame, billing systems. 57th A. Conf. American Association for Public Opinion Research, St Pete Beach.

Callegaro, M. (2004) Operator messages when calling mobile phones in Italy. Manuscript. University of Nebraska, Lincoln. Unpublished.

Callegaro, M., McCutcheon, A. and Ludwig, J. (2006) Who's calling?: the impact of caller-ID on telephone survey response. 2nd Int. Conf. Telephone Survey Methodology, Miami.

Callegaro, M. and Poggio, T. (2006) Where can I call you?: the 'mobile' revolution and its impact on survey research and coverage error: discussing the Italian case. In Recent Developments and Applications in Social Research Methodology: Proc. 6th Int. Conf. Social Science Methodology, Amsterdam, 2004 (eds C. van Dijkum, J. Blasius and C. Durand). Leverkusen-Opladen: Budrich. 
Costabile, M. and Addis, M. (2002) Comunicazione mobile in Italia; passato, presente e futuro. In Mobile Communication: Successi di Marketing nelle Telecomunicazioni Mobili in Italia (eds M. Costabile and M. Addis), pp. 23-76. Milan: Il Sole 24 Ore.

Council of American Survey Research Organizations (1982) On the definition of response rates: a special report of the CASRO task force on completion rates. Report. Council of American Survey Research Organizations, Port Jefferson. (Available from http: / / www. casro. org/resprates. cfm.)

Couper, M. P. and Lyberg, L. E. (2005) The use of paradata in survey research. 55th Sessn International Statistical Institute, Sydney.

Doxa (2003) Junior 2002: Indagine sui Comportamenti dei Ragazzi 5-13 Anni. Milan: Doxa.

Electronic Communications Committee (2005) Implementation of mobile number portability in CEPT countries. Report 31. Electronic Communications Committee, Copenhagen.

Ezzati-Rice, T., Frankel, M. R., Hoaglin, D. C., Loft, J. D., Coronado, V. G. and Wright, R. A. (2000) An alternative measure of response rate in random-digit-dialing surveys that screen for eligible subpopulations. J. Econ. Socl Measmnt, 26, 99-109.

Federal Communication Commission (2004) Ninth report. Report FC-04-216. Federal Communication Commission, Washington DC.

Frankel, L. R. (1983) The report of the CASRO task force on response rates. In Improving Data Quality in a Sample Survey: Proc. Marketing Science Institute Wrkshp, Nov. 8th, 1982 (ed. F. Wiseman), pp. 1-11. Cambridge: Marketing Science Institute.

General Accounting Office (2003) Telecommunications: FCC should include call quality in its annual report on competition in mobile phone services. Report GAO-03-501. General Accounting Office, Washington DC.

Groves, R. M. and Heeringa, S. G. (2006) Responsive design for household surveys: tools for actively controlling survey errors and costs. J. R. Statist. Soc. A, 169, 439-457.

International Telecommunication Union (2004) Mobile cellular, subscribers per 100 people. International Telecommunication Union, Geneva. (Available from http://www. itu . int/ITU-D/ict/statistics/at_ glance/cellular04.pdf.)

Ipsos (2004) EU Telecom services indicators. Report. European Commission, Brussels. (Available from http: / / europa.eu.int/information_society/policy/ecomm/doc/info_centre/studies_ ext_consult/inra_year2004/report_telecom2004_final_reduced.pdf.)

Kim, S. W. and Lepkowski, J. M. (2002) Telephone household non coverage and mobile telephones. 57th A. Conf. American Association for Public Opinion Research, St Pete Beach.

Kuusela, V. (1998) Telephone coverage in Finland. Int. BLAISE User Group Newslett., 11. (Available from http: / / www.blaiseusers.org/newsletters/bug11/fintel . htm.)

Kviz, F. J. (1977) Toward a standard definition of response rate. Publ. Opin. Q., 41, 265-267.

Lavrakas, P. J. (2005) Cell phone sampling summit II. Report. Nielsen Media Research, New York. (Available from http: / / www.nielsenmedia.com/cellphonesummit/cellphone.html.)

Lynn, P., Beerten, R., Laiho, J. and Martin, J. (2001) Recommended standard final outcome categories and standard definitions of response rate for social surveys. Working Paper 2001-23. Institute for Social and Economic Research, University of Essex, Colchester.

Lynn, P., Beerten, R., Laiho, J. and Martin, J. (2002) Towards standardisation of survey outcome categories and response rate calculations. Res. Off. Statist., 5, 61-84.

Lynn, P., Nicolaas, G., Beerten, R., Laiho, J. and Martin, J. (2006) Harmonised final outcome categories and standard definitions of response rates for UK social surveys: version 2.0. Manuscript. University of Essex, Colchester. Unpublished.

McCarty, C. (2003) Differences in response rates using most recent versus final dispositions in telephone surveys. Publ, Opin Q., 67, 396-406.

Oftel (2001) Use of Multiple SIM Cards in Mobile Phones, by Consumers in Italy, Finland \& Portugal-Summary of Oftel Research, April-May 2001. London: Office of Telecommunications.

Oftel (2003a) Consumers' Use of Fixed and Mobile Phone: Q13 May 2003. London: Office of Telecommunications.

Oftel (2003b) Consumers' Use of Fixed and Mobile Phone: Q14 August 2003. London: Office of Telecommunications.

Platek, R. and Gray, G. B. (1986) On the definitions of response rates. Surv. Methodol., 12, 17-27.

Regulatory Authority for Telecommunications and Posts (2004) Annual Report 2004. Bonn: Regulatory Authority for Telecommunications and Posts.

Robbins, K. A. and Turner, M. A. (2002) United States: popular, pragmatic and problematic. In Perpetual Contact: Mobile Communication, Private Talk, Public Performance (eds J. E. Katz and M. A. Aakhus), pp. 80-93. Cambridge: Cambridge University Press.

Roy, G. and Vanheuverzwyn, A. (2002) Mobile phone in sample surveys. Int. Conf. Improving Surveys, Copenhagen.

Shapiro, G., Battaglia, M., Camburn, D., Massey, J. and Tompkins, L. (1995) Calling local telephone company business offices to determine the residential status of a wide class of unresolved telephone numbers in a Random-Digit-Dialing sample. Proc. Surv. Res. Meth. Sect. Am. Statist. Ass., 975-980. 
Smith, T. W. (2003) A review of methods to estimate the status of cases with unknown eligibility. Report. American Association for Public Opinion Research, Lenexa.

Steeh, C., Buskirk, T. D. and Callegaro, M. (2006) Using text messages in U.S. cell phone surveys. Fld Meth., to be published.

Tucker, C., Brick, M. and Meekins, B. J. (2005a) Final results from the 2004 CPS Supplement on telephone usage. 60th A. Conf. American Association for Public Opinion Research, Miami.

Tucker, C., Brick, M. J., Meekins, B. J. and Morgenstein, D. (2005b) Household telephone service and usage patterns in the US in 2004. Proc. Surv. Res. Meth. Sect. Am. Statist. Ass., 4528-4534.

Vehovar, V., Belak, E., Batagelj, Z. and Cikic, S. (2004) Mobile phone surveys: the Slovenian case study. Metodol. Zvez., 1, 1-19. 